\title{
Presentación del número especial "COVID-19y comunicación" y una nota a favor de la Ciencia Abierta
}

Hipertext.net presenta un número especial dedicado a la COVID-19 y la comunicación. Se trata de un monográfico que queremos que sea especial en muchos sentidos. En primer lugar, por la temática, pues, aunque ya se ha escrito mucho sobre la pandemia, queda muchísimo por investigar sobre sus efectos y repercusiones en el ámbito de la comunicación.

También queremos que sea un número especial porque, por primera vez, se ha invitado a los investigadores y profesores del Departamento de Comunicación de la Universidad Pompeu Fabra a participar activamente en él. Uno de los efectos de la pandemia y el posterior confinamiento ha sido, sin duda, el aislamiento que hemos vivido durante la pasada primavera. Podernos reencontrar en este monográfico ha sido también una forma de compartir, aunque fuera de forma virtual, intereses e ideas que, habitualmente, comentamos de forma presencial en el campus de la universidad.

$Y$ en tercer lugar, queremos aprovechar la excepcionalidad de este número especial para seguir poniendo en marcha políticas editoriales de buenas prácticas a favor de la Ciencia Abierta, alineándonos, de este modo, con las directrices de transparencia en la investigación que la Comunidad Europea promueve a partir del programa Digital Science in Horizon 2020. Impulsamos y promocionamos que los autores depositen los datos (Datasets) que han servido para fundamentar los trabajo de investigación en repositorios de acceso abierto (Share Research Data) y facilitamos su gestión. Nos congratula poder informar que en este número ya contamos con trabajos que se han acogido a esta iniciativa. También hemos puesto en marcha procesos de innovación respecto a la transparencia en el proceso de revisión de los textos (Open Peer Review). Sobre este aspecto, sin embargo, debemos reconocer que hemos obtenido una acogía bastante más tibia de lo que esperábamos. Una gran mayoría de los revisores (aproximadamente un 90\%) ha preferido no constar públicamente ni hacer públicos sus comentarios. A pesar de ello, esta valiosa experiencia nos anima a mejorar el proceso de trabajo de las revisiones así como reiterar en la necesidad de seguir incorporando los principios de transparencia que defiende la Ciencia Abierta y con los que Hipertext. net se identifica.

\section{EQUIPO DE DIRECCIÓN \\ Hipertext.net \\ hipertext@upf.edu}

